\title{
Um debate sobre as condições dos docentes
}

\author{
José Alexandre da Silva ${ }^{l}$ \\ Secretaria de Estado da Educação do PR
}

$\mathrm{E}^{\mathrm{n}}$ m nossa sociedade a importância que é dada ao discurso midiático é que a midia é quato não ocorre sen motivos. É conrente a formulação de que a midia é o quarto poder e consideramos a imprensa um campo fértil de discussão sobre artigos de jornal e reportagens enfocando essa temática. Esse tipo de material, de acordo com (JEANNENEY, 2003), têm o seu ritmo: vida e morte e só se explica uma em relação às outras. Também procuramos dar uma resposta a uma crítica feita por Lima a um texto publicado anteriormente. Acreditamos que a reflexão sobre artefatos jornalísticos, envolvendo as mais variadas expressões sobre a educação, tem um papel importante para a reflexão sobre a imagem e as condições de trabalho do professor (a).

O desdobramento de um texto de opinião publicado no site do Observatório da Imprensa a nosso ver merece alguma reflexão. Chamamos a atenção para o programa Profissão Repórter que foi ao ar em sete de dezembro de dois mil e dez. Utilizamos a própria chamada do portal G1 que explica o conteúdo do programa:

Os repórteres do programa acompanharam escolas diferentes. Os repórteres Caroline Kleinübing e Caio Cavechini percorrem uma escola pública do Rio de Janeiro na qual três professoras pediram licença médica. Motivo alegado por elas: medo e depressão causados pela agressividade e pelo desinteresse dos alunos... Em Florianópolis, nosso convidado, o repórter Manoel Soares, da RBS, visita um colégio que fechou as portas depois que a diretora foi atacada com ovos e pedradas por um estudante. Salas vazias, pedaços de pau e placas de vidro apreendidos por seguranças, professores assustados e desmotivados. É este o quadro que ele registra em Santa Catarina... Caco Barcellos percorre escolas do $\mathrm{Ca}$ pão Redondo, periferia de São Paulo, e encontra muitos trabalhadores na sala de aula. Gente que luta para recuperar o tempo perdido e concilia trabalho e estudos em rotinas estafantes (SILVA, 2010).

${ }^{1}$ Professor de História da SEED-PR, Mestrando em Educação pelo PPGE da UEPG. 


\section{HUMANAS}

Os repórteres da equipe de Caco Barcelos visitaram então escolas diferentes de São Paulo, Santa Catarina e Rio de Janeiro. Se a proposta do programa é mostrar como se faz uma reportagem, o tema da reportagem figura como conteúdo secundário ou aleatório. Mas de forma alguma deixa de expressar a visão de seus idealizadores, ainda que com uma tonalidade de isenção. Ao fim do programa, constatamos que seus realizadores deixaram de forma implícita o posicionamento de que a maioria dos problemas enfrentados nas escolas eram decorrentes da apenas da inabilidade dos professores em lidar com essas questões. Utilizamos agora uma parte da conclusão da crítica tecida no texto:

[...] O contraste dos casos dos professores que enfrentam os problemas de indisciplina e de saúde e são obrigados a se afastar de sala de aula, e da professora que consegue lidar melhor com os problemas do contexto educacional. Fica o dito pelo não dito, o silenciado. $O$ fracasso da maioria colocado frente ao, suposto, sucesso de uma só. O que deixa entrever o posicionamento de que a maioria dos professores é incompetente. Das principais causas dos problemas educacionais que geram indisciplina a violência e problemas de saúde, nenhuma palavra. Assim, nas reportagens, a culpa é dos professores (SILVA, 2010).

Vindo a público, nosso pequeno texto de crítica de mídia recebeu um comentário do professor Raymundo Lima: "Alguns professores sempre se sentem atingidos por reportagens, Ora, colegas, primeiro, façam reportagens melhores, que desresponsabilizam os professores de não melhorar os indicadores do Pisa" (LIMA, 2010). Como foi mencionado acima, dedicamos alguma atenção a reportagens televisivas, artigos de jornais e revistas ou qualquer outro artefato midiático que de alguma forma envolva a educação. Nosso oficio não é realizar ou produzir reportagens visando construir uma visão mais positiva do trabalho docente ou dos professores em si. Nos interessamos, nesse caso, pela forma como os professores são representados na imprensa e que efeitos isso tem na sociedade. Entretanto, a provocação do interlocutor é um convite a uma reflexão mais consistente do que a que um pequeno texto de opinião pode veicular.

Podemos perceber que o trecho do comentário possibilita uma interpretação segundo a qual, o principal problema da educação é o despreparo dos professores. Essa tese é bastante recorrente na imprensa paulista, principalmente: Revista Veja e Jornais Folha e Estado de São Paulo. Alguns resultados preliminares que temos da análise dos artigos e reportagens que temos selecionado é de que 
esse discurso difundido por essa imprensa paulista é um grande agente legitimador das políticas educacionais dos tucanos para a educação no Estado de São Paulo. Tais políticas não foram pensadas exclusivamente para a realidade, mas se tratam de enxertos de práticas que deram certo em países com os índices mais altos em indicadores como o PISA, mencionado por Lima.

O discurso veiculado pelos meios de comunicação, mencionados acima, é simples. Com base em estudos, que raramente citam, os arautos da meritocracia apregoam aos quatro ventos que os principais problemas da educação não são os baixos salários dos professores, as turmas superlotadas e as péssimas condições de trabalho. Esses problemas são secundários, quando não, terciários. Exemplo cabal disso, temos numa formulação do economista Gustavo Ioschpe, segundo o qual, "nenhum estudo empírico que conhece aponta na direção de que turmas com menos alunos podem elevar a qualidade do ensino. Ou seja, melhor um professor excelente com uma turma de 35 alunos que dois ruins com turmas de 18" (ISCHOPE, 2010).

Uma política educacional centrada na bonificação por mérito é a aposta dos tucanos para sanar os principais problemas educacionais. As escolas paulistas que ocuparem as melhores posições num ranque criado no próprio Estado de São Paulo receberão um bônus, uma adição expressiva nos vencimentos dos professores da escola bem colocada. De acordo com esse direcionamento, se dá uma grande passo para que os bons professores com práticas inovadoras e eficientes se sintam mais motivados e continuem desempenhando seu trabalho sempre melhor. Bem como aqueles que não se saírem tão bem num primeiro momento se sintam incentivados a adotar as práticas educacionais que funcionam.

Como, nessa visão, o elemento mais atrativo para um jovem escolher sua carreira não é o item salário e atrair os melhores cérebros para a docência é condição essencial para se ter um ensino de qualidade no Brasil, a valorização por mérito, a bonificação, é o melhor caminho para o sucesso do ensino. O item financiamento da educação, assim, perde a importância. Um dos elementos que a nosso ver pode ajudar a desculpabilizar os professores da média baixa que o Brasil atinge nos indicadores internacionais nos é trazido num artigo de Frei Betto:

Análise de 39 países, feita pela OCDE em 2010, revela que o investimento do Brasil em educação corresponde a apenas $1 / 5$ do que os países desenvolvidos desembolsam para o setor. EUA, Reino Unido, Japão, Áustria, Itália e Dinamarca investem cerca de US\$94.589 (cerca de R \$160 mil) por aluno no decorrer de todo o ciclo fundamental. O Brasil investe apenas US\$ 19.516 (cerca de $\mathrm{R} \$ 33$ mil) (BETTO, 2011). 


\section{HUMANAS}

Observando os números vem a questão de porque investirmos tão pouco em comparação a outros países. Ou também porque mesmo investindo tão pouco ainda muitos de nossos governos, à frente o paulista, insistem no discurso que condições de trabalho e salários dos professores não são os problemas mais graves. O que faria um aluno brilhante escolher uma profissão mal remunerada e com condições de trabalho tão desgastantes? São questões que a nosso ver não podem ser respondidas por quem acredita que a culpa é dos professores. Se as pesquisas mencionadas por Raymundo Lima apontam que em países com os melhores indicadores nos sistemas de avaliação internacional conseguem manter os seus alunos disciplinados nas suas salas de aula, pelo que vimos acima esses países também investem muito mais em educação que o Brasil.

É interessante perceber os resultados que a remuneração por mérito deram em outros países e já estão começando a frutificar no Brasil. Tomamos a liberdade de citar outro texto nosso.

Diane Ravitch foi assistente do secretário de Educação Lamar Alexander no primeiro governo George Bush, em 1991. Após sair do governo defendia a remuneração por mérito e a generalização dos testes de avaliação. Em artigo recente, "Escolas privatizadas desempenho pífio" (Le Monde Diplomatique--Brasil, 10/2010), afirma que, observando os efeitos de tais políticas, a educação oferecida às crianças de seu país peca por problemas de gestão, de organização e de avaliação dos estabelecimentos... Os problemas elencados por Ravitch aparecem em outra versão nos depoimentos da reportagem de 19/11/10 da Gazeta do Povo. Avaliações demasiadas: "O professor só pensa na prova, em se sair bem, em tirar uma boa nota". O representante da Secretaria de Educação curitibana nega que o objetivo das avaliações seja ranquear as escolas, mas o objetivo é claro como água. Nos EUA, o objetivo das avaliações era verificar as escolas que não atingiam as metas e mudar drasticamente a gestão dessas, chegando a demitir professores, caso não conseguissem fazer seus alunos atingir o desempenho desejado. Atualmente, as escolas que perderam autonomia [conforme pontua Ravitch] não estão alcançando resultados melhores que antes e se preocupam exclusivamente em preparar os alunos para as avaliações (SILVA, 2010). 
Em resumo, ranqueamento de escolas por avaliações sistemáticas e utilizações dessas para intervenção nas instituições escolares é uma receita vinda de fora e que até mesmo no Brasil, onde o processo se encontra em fase inicial tem demonstrado resultados nefastos para o ensino. Se os professores têm problemas na sua formação isso tem de ser debatido, se somos um país com uma população heterogênea, isso se reflete na escola e temos de aprender a lidar com isso. Entretanto, a solução para nossos problemas dificilmente será acertada se continuarmos apenas a copiar as políticas que deram certo em outros locais. Pior ainda se copiarmos as que não deram. Lima prossegue em seu comentário:

[...] Está na hora de superar o discurso de "minhas impressões" (senso comum e subjetivismo) por explicações objetivas e racionais, baseadas em pesquisas científicas. Estas apontam que a indisciplina é crescente nas salas de aula, sim, e que os professores não sabem - não aprendem nos seus cursos de formação - como lidar com ela. Os primeiros lugares no Pisa são países que mantem alunos "disciplinados" em sala de aula (China, Coreia do Sul, Cuba, Chile, etc.). Muitos professores nossos se afastam da sala de aula porque sofrem alguma patologia decorrente da aversão dos alunos para aprender [não estabelecem relação-com-saber, diz Charlot) ou porque são professores que simplesmente não tem vocação para lidar com o "pacote" ( saber ensinar, lidar com diferenças, indisciplina, etc.).

Como vemos acima, Lima afirma que o "subjetivismo" e o "senso comum" tem de dar lugar aos resultados de pesquisas científicas. Pesquisas que confirmam que os professores não estão preparados para lidar com indisciplina, a indisciplina que não está presente nos países bem avaliados no PISA. A colocação nos faz lembrar de uma crítica feita pelo professor Gabriel Perissé a um dos textos do economista Gustavo Ioschpe. Esse, que se auto define especialista em educação, costuma mencionar em seus artigos que o conteúdo dos mesmos é embasado em pesquisas empíricas. Acontece que raramente cita quais pesquisas são. Evidente que não esperávamos que Lima dissesse em seu comentário a quais pesquisas se referia, mas a simples menção a pesquisas já serve para nos fazer refletir sobre alguns elementos que envolvem a atual pesquisa educacional no Brasil.

Podemos dizer que a agenda educacional seguida por nossos governos nos últimos anos são pautadas necessariamente por demandas externas. 


\section{HUMANAS}

Índices conseguidos por organismos internacionais que têm mecanismos de pressão para forçar os governos a implementar determinadas políticas (FONSECA, 1998). Foi assim com a universalização do ensino iniciada na década de 1990. Em nosso país podemos dizer que o escolarização foi imposta às classes mais baixas, não devido a uma consciência ampla e geral no país de que a população precisava ser escolarizada, mas devido à imposição desses organismos internacionais. Assim, a universalização do ensino foi construída no Brasil às custas dos baixos salários dos professores. Vejamos:

O assessor especial da Organização das Nações Unidas para a Educação, a Ciência e a Cultura (Unesco), Célio da Cunha, alerta que o problema de desvalorização é antigo... "A universalização do ensino fundamental foi feita à custa dos baixos salários dos professores. Quando se expandiu o número de escolas e fez-se a inclusão de mais alunos, ironicamente foram os professores que financiaram isso porque a expansão não foi feita melhorando a carreira e os salários", avalia (CIEGLINSKI, 2010).

Reflexões como essa não foram levadas em conta nas considerações de Lima.

O dilema em que e encontra a pesquisa educacional no Brasil é que essa produção científica passe a se preocupar de fato com as necessidades educacionais que temos. Uma produção científica que não siga a agenda dos organismos internacionais que tê orientado nossas políticas educacionais. Para que a pesquisa educacional atinja esse parâmetro urge a necessidade de pesquisas menos particularizadas, que possibilitem o alcance também de uma dimensão quantitativa. Essa dimensão têm sido rejeitada nos últimos tempos em virtude de serem mal utilizadas no passado, de modo a que amontoados de índices e dados fossem apenas aventados sem uma reflexão qualitativa. Têm-se privilegiado então pesquisas assemelhadas a estudos de caso ou com dados de pouca representatividade. Vejamos:

[...] Há que se destacar que a utilização crescente das novas metodologias exploratórias/qualitativas decorre da composição de amostras intencionais ou arbitrárias, muito reduzidas e predominantemente constituídas de alguns sujeitos; no caso das descritivas narrativas, a "amostra" é o próprio autor que expõe sua "experiência" ou "vivência" (GATTI, 2001; p. 76). 
Com pesquisas de natureza, abarcando um espectro mais amplo e refinado, poderemos mapear as principais necessidades e problemas do meio educacional, bem como propor soluções mais eficazes. Nesse sentido, a provocação de Lima citada acima, "Ora, colegas, primeiro, façam reportagens melhores, que desresponsabilizam os professores de não melhorar os indicadores do Pisa", perde seu sentido. Temos de produzir sim pesquisas que desresponsabilizam os professores. Não podemos aceitar que a má avaliação do Brasil nos índices internacionais se deva apenas à incompetência docente, lembrando que, "o investimento do Brasil em educação corresponde a apenas $1 / 5$ do que os países desenvolvidos desembolsam para o setor", como lembra Frei Beto no texto citado acima. Acreditamos que a má situação do Brasil em comparação a outros países seja de natureza multicausal. Compreendendo principalmente deficiências de estrutura, falta de salas de aula, quadras poliesportivas e espaços agradáveis. Também baixos salários, o que torna a profissão pouco atraente para os alunos mais destacados.

Na seqüência de seu comentário, Raymundo Lima afirma que os professores brasileiros não conseguem manter seus alunos disciplinados por terem patologias decorrentes da aversão dos alunos por aprender ou por não terem vocação para administrar as questões para lidar com a complexidade do campo educacional. Esse último ítem, nas palavras do autor, se refere a falta de vocação para lidar com o "pacote" (saber ensinar, lidar com diferenças, indisciplina, etc.). Temos de lembrar que o termo vocação é ligado a um elemento religioso. Assim, o professor é aquele que tem vocação para lecionar. Pois se não tem, não sabe lidar com todo um pacote. Entretanto, vocação é algo inato, nasce com a pessoa. O professor então é privado do aprender a ser professor, do treinamento acadêmico e da formação universitária. Tem que ter vocação, algo que já nasceu com ele. Vale recorrer, nesse caso, a uma formulação de (CURY, 2011): Não é admissivel que alguém lecione apenas porque gosta de crianças ou acredita que leva jeito. A docência exige conhecimentos científicos.

Essa concepção que interliga a educação com a religiosidade talvez não seja de se estranhar. Temos de lembrar que na fase colonial do Brasil a educação ficou a cargo dos padres jesuítas. Essa ordem foi criada no contexto da contra-reforma como uma reação da Igreja Católica ao surgimento das igrejas protestantes. Esses religiosos se espalharam por todo o mundo para levar o evangelho em moldes do cristianismo católico. No Brasil, os principais alvos dos jesuítas eram os indígenas, como almas para serem evangelizadas e portanto salvas. Vem daí as concepções de educação ligadas à concepções religiosas. Concepções que infelizmente, a nosso ver, fazem perder de vista a dimensão profissional do ensino. Ser professor (a) é uma profissão, não uma missão. 


\section{HUMANAS}

É como profissão ou categoria profissional que nós educadores temos que trazer a público as mazelas de nosso ofício. Afinal, ninguém as conhece melhor que nós. É de grande importância e uma grande responsabilidade contrapor as visões e imagens equivocadas sobre a profissão docente num campo com tamanho poder de gerar representações como a grande mídia. Essa, cumpre bem o papel de construtora e difusora de representações negativas. Contraditoriamente, também encontramos nesse campo alguns lampejos de sobriedade com os quais pretendemos fechar esse texto. Como vimos acima, a situação da educação no Brasil não é um acaso e sim um projeto, um desejo, para usar uma expressão de (JABOR, 2010). Cabe a nós educadores desejar e construir um projeto melhor.

\section{Referências bibliográficas}

BETTO, Frei. Ações do documento Educação: da quantidade à qualidade. Correio Brasiliense, 14 de Janeiro de 2011.

CIEGLINSKI, A. Magistério tem dificuldades de atrair jovens talentos para a carreira. Jornal da Ciência. In: http://www.jornaldaciencia.org.br (acesso: 9 de Maio de 2011).

FONSECA, M. O Banco Mundial como referência para a justiça social no terceiro mundo: evidências do caso brasileiro. Revista da Faculdade de Educação, v.24, n.1, 1998.

FERNANDES, E. 15 mitos da Educação. In: http://revistaescola.abril.com.br/ formacao (acesso: 9 de Maio de 2011).

GATTI, B.A. Implicações e perspectivas da pesquisa educacional no Brasil contemporâneo. Cadernos de Pesquisa, 113: 65-81, 2001.

IOSCHPE, G. Como melhorar a educação brasileira - Parte 1. Veja, pp. 94-96, 10 de Novembro de 2011.

LIMA, R. Comentário. In: J.A. SILVA. Profissão Repórter, a culpa é dos professores. Observatório da Imprensa. In: http://www.observatoriodaimprensa.com.br/ artigos (acesso: 6 de Maio de 2011.

JABOR, A. Comentário. In: J.A. SILVA. O mesmo tema, abordagens diferentes. Observatório da Imprensa. In: http://observatoriodaimprensa.com.br/artigos (acesso: 9 de Outubro de 2011).

JEANNENEY, J.-N. A mídia. In: R. REMOND. Por uma História política. Pp. 213-30. Rio de Janeiro: Editora FGV, 2003. 
PERISSÉ, G. Sobre elites e elitismos. Observatório da Imprensa. In: http:// www.observatoriodaimprensa.com.br/artigos (acesso: 6 de Maio de 2011.

PERISSÉ, G. Por um melhor jornalismo educacional. Observatório da Imprensa. In: http://www.observatoriodaimprensa.com.br/artigos (acesso: 9 de Maio de 2011).

RAVITCH, D. Escolas privatizadas desempenho pífio. Le Monde Diplomatique Brasil. In: http://pt.scribd.com/doc/42451617/Escolas-privatizadas-desempenho-Pifio (acesso: 9 de Maio de 2011.

SILVA, J.A. A culpa é dos professores. Observatório da Imprensa. In: http:/ /www.observatoriodaimprensa.com.br/artigos (acesso: 6 de Maio de 2011).

SILVA, J.A. Educação sempre em pauta. Observatório da Imprensa. In: http:/ /www.observatoriodaimprensa.com.br/artigos (acesso: 6 de Maio de 2011). 